\title{
CARBON WIRE HEATING DUE TO SCATTERING IN THE SNS
}

\author{
C. J. Liaw and P.R. Cameron, BNL, Upton, NY 11973, USA
}

\begin{abstract}
In the SNS, the $2.5 \mathrm{MeV} \mathrm{H}^{-}$beam from the RFQ will be accelerated in the Linac to $1 \mathrm{GeV}$, and then injected into the High Energy Beam Transport (HEBT). After passing through HEBT, the electrons are stripped during injection into the Accumulator Ring. The proton beam will be accumulated in the Ring for around 1000 turns before ejecting to the Ring to Target Beam Transport (RTBT). The filling time of the Ring will be $1 \mathrm{~ms}$ and the extraction pulse length from the ring will be $695 \mathrm{~ns}$, with a repetition rate of $60 \mathrm{~Hz}$. The baseline power per pulse of the proton beam is $1 \mathrm{MW}$, with the possibility of a 2 MW upgrade. Carbon wires will be used to measure beam profiles throughout the facility. Wire heating due to beam scattering by the carbon wires has been analyzed from the RFQ through to the RTBT. We present results from this analysis.
\end{abstract}

\section{INTRODUCTION}

Carbon wires will be used to measure the beam profiles in the Spallation Neutron Source (SNS) [1]. The $2.5 \mathrm{MeV}$ $\mathrm{H}^{-}$beam from the RFQ will be accelerated in the Linac to around $1 \mathrm{GeV}$ and injected into the HEBT. After stripping the electrons, the $1 \mathrm{GeV}$ proton beam will be accumulated in the Ring for around 1000 turns before ejecting to RTBT. The filling time of the Ring will be $1 \mathrm{~ms}$ and the extraction pulse length from the ring will be $695 \mathrm{~ns}$, with a repetition rate of $60 \mathrm{~Hz}$ [2]. The maximum power per pulse of the proton beam will be from $1 \mathrm{MW}$ operation to 2 MW upgrade.

\section{METHODS}

\subsection{General Assumptions}

The general assumptions for the analyses are as follows:

1. Heating due to beam fields and thermionic emissions are negligible.

2. The scattering heats the wire with a heating efficiency, $\eta$, as shown below: [3]

\begin{tabular}{|l|l|l|l|l|l|l|}
\hline $\mathrm{MeV}$ & 2.5 & 100 & 200 & 500 & 1000 & 1300 \\
\hline$\eta, \%$ & 100 & 98 & 89 & 87 & 82 & 79 \\
\hline
\end{tabular}

3. Carbon wire diameter: $32 \mu \mathrm{m}$.

4. Thermal properties of carbon:[4]

Density $=\rho=2000 \mathrm{~kg} / \mathrm{m}^{3}$

Radiant Emissivity $=\varepsilon=0.8$

Heat capacity $=\mathrm{c}=12.7+2.9 \mathrm{~T}-1.4 \times 10^{-3} \mathrm{~T}^{2}+3.1 \times$ $10^{-7} \mathrm{~T}^{3}-2.4 \times 10^{-11} \mathrm{~T}^{4} \quad[\mathrm{~J} / \mathrm{Kg}-\mathrm{K}]$

5. Heat conduction along the carbon wire is negligible.

\subsection{Power Densities on the Carbon Wire}

The beam power loss density, $\mathrm{P}$, through the carbon wire can be estimated using the following equations:

For $2.5 \mathrm{MeV} \sim 1 \mathrm{GeV} \mathrm{H}^{-}$beam:

$$
\mathrm{P}=1 / \rho(\mathrm{dE} / \mathrm{dx})_{\mathrm{p}} \rho \mathrm{I} \mathrm{x}+2 \mathrm{P}_{\mathrm{e}}
$$

For $1 \mathrm{GeV}$ proton beam:

$$
\mathrm{P}=1 / \rho(\mathrm{dE} / \mathrm{dx})_{\mathrm{p}} \rho \mathrm{Ix}
$$

where $\mathrm{P}=$ power/area $\left[\right.$ watts $\left./ \mathrm{m}^{2}\right]$,

$$
\begin{aligned}
\mathrm{P}_{\mathrm{e}} & =1 / \rho(\mathrm{dE} / \mathrm{dx})_{\mathrm{e}} \rho \mathrm{Ix} \quad\left(1 / \rho(\mathrm{dE} / \mathrm{dx})_{\mathrm{e}} \mathrm{x}<\mathrm{P}_{\mathrm{s}}\right) \\
& =\mathrm{P}_{\mathrm{s}} \quad\left(1 / \rho(\mathrm{dE} / \mathrm{dx})_{\mathrm{e}} \mathrm{x}>=\mathrm{P}_{\mathrm{s}}\right) \\
\mathrm{P}_{\mathrm{s}} & =\text { power to stop an electron beam }[\mathrm{eV}], \\
\mathrm{I} & =\text { beam current density }\left[\mathrm{A} / \mathrm{m}^{2}\right] \\
\mathrm{x} & =\text { average wire thickness }[\mathrm{m}]=\pi \mathrm{d} / 4 \text { (Fig. } 1) .
\end{aligned}
$$

$1 / \rho(\mathrm{dE} / \mathrm{dx})_{\mathrm{p}}$ and $1 / \rho(\mathrm{dE} / \mathrm{dx})_{\mathrm{e}}=$ Collision energy loss of the proton and the electron beam through the carbon wire $\left[\mathrm{MeV} / \mathrm{g} / \mathrm{cm}^{2}\right][5]$. The factor 2 in Eq. (1a) represents two electrons in a $\mathrm{H}^{-}$beam. The deposition power density on the carbon wire is the product of the beam power loss density and the heating efficiency.

$$
\begin{aligned}
& A=\pi d^{2} / 4 \\
& x=A / d=\pi d / 4
\end{aligned}
$$

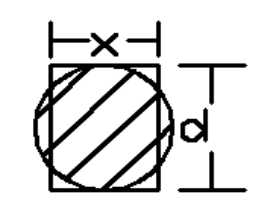

Figure 1: Definition of the average wire thickness

\subsection{Governing Equation}

Since the heat conduction along the carbon wire is small compared with the heat transfer through radiation [6], the temperature variations on the carbon wire can be simplified to [6,7]:

$\mathrm{dT} / \mathrm{dt}=4 /(\rho \pi \mathrm{dc})\left(\mathrm{P} \eta-\pi \sigma \varepsilon\left(\mathrm{T}^{4}-\mathrm{T}_{\mathrm{o}}^{4}\right)\right)$

where $\mathrm{T}=$ wire temperature $[\mathrm{K}]$

$\mathrm{T}_{\mathrm{o}}=$ beam pipe temperature $=297[\mathrm{~K}]$

$\mathrm{d}=$ diameter of the wire $[\mathrm{m}]$

$\mathrm{t}=$ time $[\mathrm{sec}]$

$\sigma=5.67 \times 10^{-8}\left[\mathrm{~W} / \mathrm{m}^{2} \mathrm{~K}^{4}\right]$

and $\rho, \varepsilon, c, \eta$ and $P$ are defined in Section 2. 


\section{ANALYSES AND RESULTS}

\subsection{Stationary Wire}

The maximum temperatures with the stationary wire condition for the injection line (from MEBT to HEBT), the ring and RTBT, are analyzed below:

\subsubsection{Injection Line}

For setup and diagnostics purposes the $2.5 \mathrm{MeV}$ to 1 $\mathrm{GeV} \mathrm{H}^{-}$beam could operate with a mean current, over a pulse, of $16 \mathrm{~mA}$ (1 MW case) or $36 \mathrm{~mA}$ ( $2 \mathrm{MW}$ case), and with three possible combinations of repetition rates and pulse lengths: $60 \mathrm{~Hz} / 1 \mathrm{~ms}, 6 \mathrm{~Hz} / 1 \mathrm{~ms}$, and $6 \mathrm{~Hz} / 50 \mu \mathrm{s}$. The minimum $\sigma_{\mathrm{x}}$ and $\sigma_{\mathrm{y}}$ of beam, at the beam profile monitor locations, is $1.97 \mathrm{~mm}$ by $1.11 \mathrm{~mm}$ in MEBT and is $1.4 \mathrm{~mm} \times 1.4 \mathrm{~mm}$ in HEBT. The $\sigma_{\mathrm{x}}$ and $\sigma_{\mathrm{y}}$ of the injected beam, between MEBT and HEBT, are from 0.8 $\mathrm{mm}$ to $3.5 \mathrm{~mm}$, which are shown in [8]. Assuming a 2-D Gaussian distributed beam in the injection line, the maximum current density of the beam is

$$
I_{\max }=\mathrm{I} /\left(2 \pi \sigma_{\mathrm{x}} \sigma_{\mathrm{y}}\right)
$$

where $\mathrm{I}$ is the mean beam current over a pulse $\left[\mathrm{A} / \mathrm{m}^{2}\right]$, and $\sigma_{\mathrm{x}}, \sigma_{\mathrm{y}}$ are sigma of the beam in the $\mathrm{x}$ and $\mathrm{y}$ direction. The maximum deposition power density per unit maximum beam current density on the carbon wire vs. beam energy is shown in Fig. 2 (calculated from Eq. (1a)).

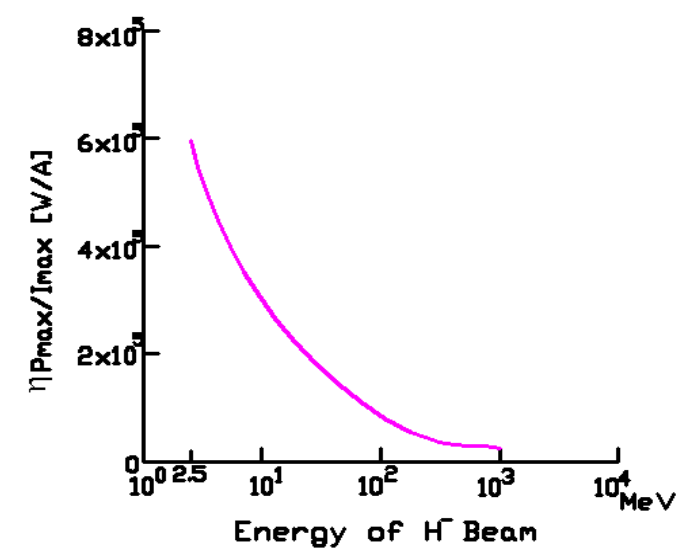

Figure 2: Max. deposition power density/ max. beam current density on the wire vs. $\mathrm{H}^{-}$beam energy

By substituting the material and geometric properties of the carbon wire, Eq. (2) becomes

$\mathrm{dT}_{\max } / \mathrm{dt}=\left[19.9 * \eta \mathrm{P}_{\max }-2.83 \times 10^{-6} *\left(\mathrm{~T}_{\max }{ }^{4}-\mathrm{T}_{\mathrm{o}}{ }^{4}\right)\right] / \mathrm{c}$

After integrating Eq. (4), the maximum wire temperatures in the injection line are shown in Fig. 3 and Fig. 4 for the selected operating conditions. (See the continuous lines.)

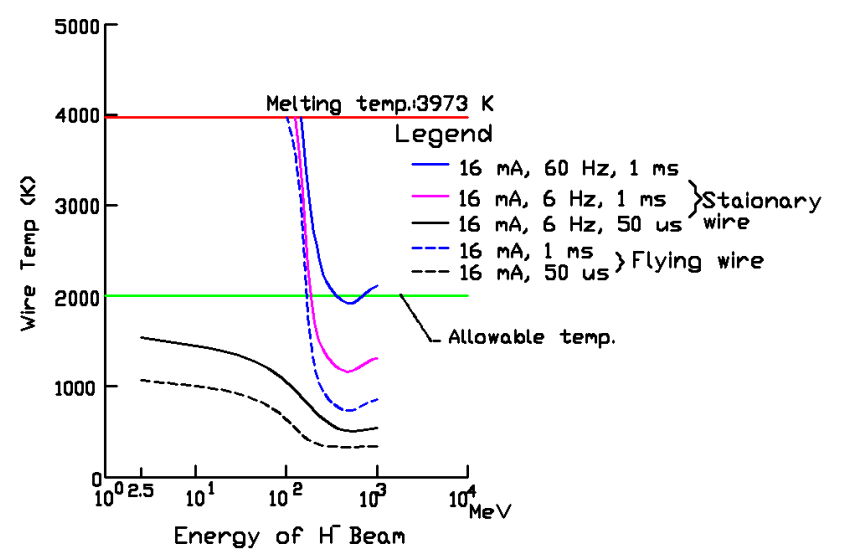

Figure 3: Maximum wire temperatures vs. beam energy in

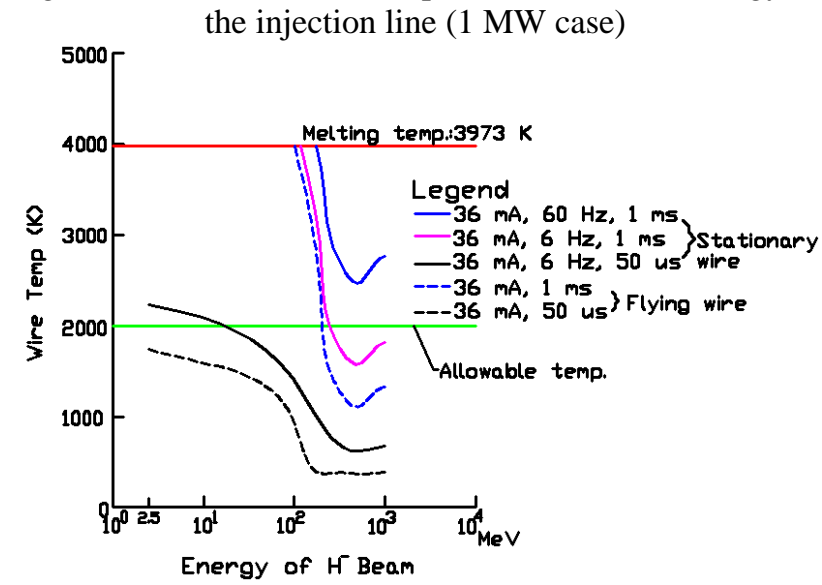

Figure 4: Maximum wire temperatures vs. beam energy in the injection line ( $2 \mathrm{MW}$ case)

\subsubsection{Accumulator Ring}

According to the injection painting scheme [2], the beam size $(\mathrm{H} \times \mathrm{V})$ inside the accumulator ring will increase from $3.1 \mathrm{~mm} \times 3.8 \mathrm{~mm}$ at the beginning of the injection cycle to a full size of $56 \mathrm{~mm} \times 68 \mathrm{~mm}$ before ejecting to the RTBT. The maximum beam current density was estimated by increasing the mean current density by $25 \%$. The maximum deposition power density $\left(\eta \mathrm{P}_{\max }\right)$ within the $1 \mathrm{~ms}$ heating process is $1.28 \times 10^{8} \mathrm{t} / \mathrm{A}$ and $2.56 \times 10^{8} \mathrm{t} / \mathrm{A}\left[\mathrm{W} / \mathrm{m}^{2}\right]$ for the $1 \mathrm{MW}$ and $2 \mathrm{MW}$ case respectively (using Eq. $1 \mathrm{~b}$ and considering the 1000 turns accumulation), where $\mathrm{t}=$ time $[\mathrm{s}]$ and $\mathrm{A}=6.45 \times 10^{-6}+3.09$ $*_{t}\left[\mathrm{~m}^{2}\right]$. After integrating Eq. (4), the maximum wire temperature in the accumulator ring is $2231 \mathrm{~K}$ for the 1 MW case and is $2826 \mathrm{~K}$ for the $2 \mathrm{MW}$ case.

\subsubsection{RTBT}

The beam size $(\mathrm{H} \times \mathrm{V})$ will vary from $56 \mathrm{~mm} \times 68 \mathrm{~mm}$ (out of the ring) to $70 \mathrm{~mm} \times 200 \mathrm{~mm}$ (at the target area). The smaller beam size was used in the following calculation to obtain a conservative result. Since the beam profile inside the ring will be "quasi-uniform"[2], the maximum beam current density was estimated by increasing the mean current density by $25 \%$. The maximum deposition power density $\left(\eta \mathrm{P}_{\max }\right)$, within the $695 \mathrm{~ns}$ heating process, is $0.6 \times 10^{8}$ and $1.2 \times 10^{8}\left[\mathrm{~W} / \mathrm{m}^{2}\right]$ 
for the $1 \mathrm{MW}$ and $2 \mathrm{MW}$ case respectively (using Eq. (1b)). After integrating Eq.(4), the time evolutions of the maximum wire temperature in the RTBT is $396 \mathrm{~K}$ for the $1 \mathrm{MW}$ case and $460 \mathrm{~K}$ for the $2 \mathrm{MW}$ case.

\subsection{Crawling And Flying Wires}

A single carbon wire can be used to measure the beam profile by either crawling or flying the wire across the beam. The maximum velocity for a crawling wire is limited by the requirement that there are a sufficient number of points in the beam profile. For example: If a single point of the profile results from each $1 \mathrm{~ms} 60 \mathrm{~Hz}$ pulse, and we ask for 40 points over $4 \sigma$ of a $1.2 \mathrm{~mm}$ rms beam (the minimum sized beam in HEBT), then the maximum velocity for a crawling wire is on the order of 7 $\mathrm{mm} / \mathrm{s}$. Similarly if using the reduced rep rate of $6 \mathrm{~Hz}$ as the diagnostics mode, the maximum velocity would be $0.7 \mathrm{~mm} / \mathrm{s}$. For crawling wires, the maximum temperatures would be essentially the same as the long time limit for stationary wires. (See Section 3.1.).

Given that the purpose of flying the wire is to limit temperature rise, the minimum velocity for a flying wire is determined by the requirement that the wire remains in the beam for only a single pulse. For example: For $4 \sigma$ of a $2 \mathrm{~mm} \mathrm{rms}$ beam (the maximum sized beam in HEBT), the minimum flying wire velocity for a $1 \mathrm{~ms}$ long beam pulse would be $8 \mathrm{~m} / \mathrm{s}$ and would be $160 \mathrm{~m} / \mathrm{s}$ for a $50 \mu$ s long beam pulse. For flying wires the maximum temperature would be the same as a single pulse on a stationary wire. The maximum wire temperatures of the flying wire in the injection line are shown in Fig. 3 and Fig. 4 (see the dashed line). The maximum wire temperature in the ring would be $936 \mathrm{~K}$ and $1380 \mathrm{~K}$ for the $1 \mathrm{MW}$ and $2 \mathrm{MW}$ case respectively and would be below $299 \mathrm{~K}$ in RTBT.

\section{CONCLUSIONS \& DISUSSIONS}

By taking into account the lifetime of the carbon fiber, a wire temperature of $2000 \mathrm{~K}$ is considered to be the limit of the wire temperature $[9,10]$. For both the stationary and the flying wire condition in the injection line, the carbon wire could possibly survive in the entire line with a $6 \mathrm{~Hz} / 50 \mu$ s beam. With a $60 \mathrm{~Hz} / 1 \mathrm{~ms}$ and $6 \mathrm{~Hz} / 1 \mathrm{~ms}$ beam, however, the carbon wire could only be used in the higher energy region. For the ring, the carbon wire could only survive under the flying wire condition. Since the wire temperature in RTBT is below $460 \mathrm{~K}$ for the stationary wire condition and is below $299 \mathrm{~K}$ for the flying wire case, lifetime of the carbon wire is not an issue in this region.

\section{REFERENCES}

[1] SNS CDR Report (NSNS/CDR-2), 1997 http://server.ags.bnl.gov/bnldag/sns.html

[2] SNS Project Design Manual, 1999, BNL http://server.ags.bnl.gov/bnlags/bnlsns/sns.html

[3] C. Fischer, CERN-CH-1211

[4] Handbook of Materials Science, CRC Press, $2^{\text {nd }}$ ed..

[5] M.J. Berger, “ Stopping Power and Range Table for Electrons, Protons, and Helium Ions", NISTIR 4999. http://physics.nist.gov/PhysRefData/Star/Text/contents.ht $\underline{\mathrm{ml}}$

[6] C.J. Liaw, et al, "Calculation of the maximum temperature on the carbon stripping foil of the Spallation Neutron Source", PAC 1999, New York.

[7] J. P. Holman, Heat Transfer $5^{\text {th }}$ ed., McGraw-Hill.

[8] Harunori Takeda, "End to End Simulations", SNS Progress Review, September 11, 2000.

[9] M. Wilke et al., "Status and Test Report on the LANL-Boeing Flying-Wire-Profile Monitor", LANL status report:LA-12732-SR, July 1994.

[10] C. Field, et al, "Wire Breakage in SLC Wire Profile Monitors", SLAC, CP451, BIW 1998. 